\title{
Astrocyte Calcium Responses to Sensory Input: Influence of Circuit Organization and Experimental Factors
}

\author{
Mónica López-Hidalgo ${ }^{\dagger}$, Vered Kellner ${ }^{\dagger}$ and James Schummers * \\ Max Planck Florida Institute for Neuroscience, Jupiter, FL, USA
}

Keywords: astrocyte, visual cortex, calcium, in vivo imaging

\section{INTRODUCTION}

\section{OPEN ACCESS}

Edited by:

Kira Poskanzer,

University of California, San Francisco,

USA

Reviewed by:

Hajime Hirase,

RIKEN Brain Science Institute, Japan

Todd Fiacco

University of California, Riverside, USA

${ }^{*}$ Correspondence:

James Schummers

james.schummers@mpfi.org

${ }^{\dagger}$ Present Address:

Mónica López Hidalgo,

Facultad de Medicina, Universidad

Autónoma de Querétaro, Querétaro,

Mexico

Vered Kellner,

Solomon H. Snyder Department of Neuroscience, Johns Hopkins University School of Medicine, Baltimore, MD, USA

Received: 31 January 2017 Accepted: 24 February 2017 Published: 22 March 2017

Citation:

López-Hidalgo M, Kellner V and Schummers J (2017) Astrocyte Calcium Responses to Sensory Input: Influence of Circuit Organization and

Experimental Factors.

Front. Neural Circuits 11:16.

doi: 10.3389/fncir.2017.00016
Astrocytes are important partners to neurons due to their involvement in homeostatic functions (Olsen et al., 2015; Verkhratsky et al., 2015), synaptic transmission (Perea and Araque, 2007; Di Castro et al., 2011; Panatier et al., 2011), synaptic plasticity (Perea and Araque, 2007; Min and Nevian, 2012; Valtcheva and Venance, 2016), and cognitive functions (Han et al., 2012; LópezHidalgo et al., 2012; Lee et al., 2014; Lima et al., 2014; Matos et al., 2015). These essential functions involve activation of calcium signaling pathways within the cytosol of the astrocyte, which can be activated intrinsically (Nett et al., 2002; Srinivasan et al., 2015; Rungta et al., 2016), or in response to neuronal activity (Di Castro et al., 2011; Haustein et al., 2014). Defining the quantitative relationship between neuronal activity and astrocyte calcium signaling has proven difficult. Early results in cultured astroglial cells demonstrated that neuronal activity can trigger calcium events which exhibit a number of distinct properties, including oscillations and traveling waves (CornellBell et al., 1990; Parpura et al., 1994; Dani and Smith, 1995), which propagate throughout gapjunction coupled networks of cells, leading to the notion that astrocytes function as a syncytium (Finkbeiner, 1992; Giaume and Venance, 1998). Subsequent studies of astrocytes in situ, primarily in acute hippocampal slices, painted a different picture of astrocyte calcium activity; many small events were localized to individual branches, global cell-wide events were rare, and intercellular waves were very sporadic (Nett et al., 2002; Fiacco and McCarthy, 2004; Shigetomi et al., 2013a; Haustein et al., 2014). It was soon recognized that variations in tissue preparation, stimulation protocol, and other experimental factors might play a role in these differences. An important realization was that astrocytes readily adapt to surrounding conditions, and that even subtle experimental changes in physiological conditions can have profound effects on astrocyte calcium signaling (Takano et al., 2014; Mola et al., 2016).

It was hoped that some of these issues might be resolved by measuring astrocyte calcium activity in vivo during physiological activation of neuronal circuits, which was made possible with advances in both indicator labeling and imaging technologies (Denk et al., 1990; Stosiek et al., 2003; Nimmerjahn et al., 2004; Helmchen and Denk, 2005; Shigetomi et al., 2013b). Most in vivo studies of astrocytes have attempted to activate astrocyte calcium pathways by driving neuronal activity with sensory stimulation. Sensory-evoked calcium responses in astrocytes have been shown in the spinal cord (Sekiguchi et al., 2016), olfactory bulb (Petzold et al., 2008; Otsu et al., 2015), somatosensory cortex (Winship et al., 2007; Schulz et al., 2012; Ghosh et al., 2013; Zhang et al., 2016), barrel cortex (Wang et al., 2006), and visual cortex (Schummers et al., 2008).

However, studies with seemingly similar experimental design have led to different conclusions. While early studies reported robust astrocyte calcium activity in response to sensory stimulation (Wang et al., 2006; Schummers et al., 2008), recent studies have shown weak, sporadic, or 
non-existent responses to sensory stimulation in both visual (Bonder and McCarthy, 2014; Paukert et al., 2014; Asada et al., 2015) and somatosensory (Ding et al., 2013; Nizar et al., 2013) cortex. Interestingly, several of these studies noted stronger responses to neuromodulators than to sensory stimulation (Chen et al., 2012; Ding et al., 2013; Paukert et al., 2014). Taken together with the recent demonstration that mGluRs-initially thought to be responsible for neuronal-driven responses-may not be expressed in adult astrocytes (Sun et al., 2013), confusion has emerged as to whether astrocytes respond robustly to local synaptic activity in vivo.

Here, we attempt to reconcile the seemingly contradictory results in the literature and to synthesize an understanding of astrocyte calcium signaling that incorporates observations in different experimental preparations. We summarize fundamental differences in the neuronal circuit and astrocyte organization, sensory-evoked neuronal dynamics as well as technical issues involved in these studies that play important roles in the different patterns of astrocyte responses. We argue that apparently different results can be reconciled by considering these factors. Altogether, we propose a synthesis of the existing literature that astrocytes integrate signals from a variety of sources, including local synaptic activity and neuromodulators, but only generate calcium responses subject to a relatively high threshold. It remains unknown whether this threshold applies equally to somatic and subcellular responses in more distal portions of astrocyte processes, though in vitro responses to electrical stimulation suggest a similar threshold in both compartments (Haustein et al., 2014). Since most in vivo studies have focused on somatic or global responses, we will focus mostly on these, but we note that subcellular responses are a topic of ongoing investigation and may provide additional insight into neuronastrocyte communication.

\section{VISUAL SYSTEM IN FERRETS AND RODENTS: NEURONAL CIRCUITS}

The most disparate results have come in studies of visual cortical astrocytes. One difference between the contradictory studies is the use of different species. While visually-evoked calcium responses in ferret visual cortex astrocytes are robust and highly tuned to visual stimuli (Schummers et al., 2008), in mice, visual responses in astrocytes are generally reported to be weak, unreliable, or sparse (Bonder and McCarthy, 2014; Paukert et al., 2014; Asada et al., 2015; though see Chen et al., 2012). An understanding of the differences between the functional organization of rodent and ferret visual cortex may shed light on this apparent conflict.

Given that astrocyte calcium responses are driven by synaptic activity, it is important to consider the spatio-temporal patterns of neuronal activity that a visual stimulus, such as a grating, would be expected to evoke in each species. In primates and carnivores including ferrets, primary visual cortex (V1) is organized in vertical columns according to preferred orientation (Figure 1A, left; Hubel and Wiesel, 1962; Grinvald et al., 1986; Chapman et al., 1996). Rodents do not have this organization; preferred orientation is spatially random, in a so-called salt-andpepper arrangement (Figure 1A, right; Dräger, 1975; Mangini and Pearlman, 1980; Ohki et al., 2005; Ohki and Reid, 2007; Kondo et al., 2016; Ringach et al., 2016).

Owing to the columnar organization of orientation preference in ferret, we would expect the majority of neurons within the territory of an astrocyte to respond together to a grating of the preferred orientation (Figure 1B, left). In contrast, based on the typical half-width of mouse tuning curves $\left(\sim 25^{\circ}\right.$; Niell and Stryker, 2008), a simulation of the responses in a salt-and-pepper cortex to a particular orientation (Figure 1B, right), would drive responses in only a small fraction of the neurons in the territory of a mouse astrocyte ( $\sim 27 \%$ of neurons would have a strong response, defined as $>50 \%$ of max response; Figure 1C, right). Furthermore, firing rates evoked by a grating stimulus are nearly three times higher in ferret $(\sim 19 \mathrm{~Hz} ; \mathrm{M}$ Popović and SD Van Hooser, personal communication) than in mouse visual cortex ( $\sim 7 \mathrm{~Hz}$; Niell and Stryker, 2008; Durand et al., 2016). Thus, during the presentation of an oriented grating, an astrocyte in ferret visual cortex would receive input from more neurons (fourfold) which fire more action potentials (three-fold), which means 12 times more synaptic activity than an astrocyte in mouse visual cortex (See Figure 1C). Considering that astrocyte responses are thought to derive from transmitter spillover (Patrushev et al., 2013), it is likely that this would result in a considerable difference in the amount of transmitter available to astrocyte receptors or transporters. The combined difference in synapse number and firing rate is likely to have a dramatic effect on determining whether the integrated activity reaches threshold to activate astrocyte calcium signaling.

One might then ask: if astrocyte calcium responses depend on such strong concerted activation, would they ever be activated in mouse visual cortex? In other words, are the types of responses observed in ferret cortex the exception, rather than the rule? We would argue that these differences are a consequence of the experimental approach to studying visual cortex, which does not take into account important differences in the functional organization of the visual systems between the species. In particular, several lines of evidence suggest that V1 might not serve the same function in the visual hierarchy in rodents as in carnivores. In cats, ferrets and primates, visual information from the eye is processed in the retinal ganglion cells and most of the projections are sent to the lateral geniculate nucleus (LGN) which in turn drives neurons in V1 (Reid and Alonso, 1995; Hirsch et al., 1998; Alonso et al., 2001). In rodents, only 50\% of retinal ganglion cells reach the visual cortex through the LGN (Martin, 1986; Gauvain and Murphy, 2015; Ellis et al., 2016). Instead, the majority of these projections $(\sim 70-90 \%)$ reach the superior colliculus (Linden and Perry, 1983a,b; Hofbauer and Dräger, 1985; Ellis et al., 2016), where in fact, orientation maps have been observed (Ahmadlou and Heimel, 2015; Feinberg and Meister, 2015; Inayat et al., 2015). This suggests the possibility that substantial processing in rodents occurs in subcortical structures and that V1 could serve as a higher-order visual area. Consistent with this, the activity of V1 neurons in rodents reflects multimodal processing of visual and locomotor signals (Niell and Stryker, 2010; Keller et al., 2012; Ayaz et al., 2013; 


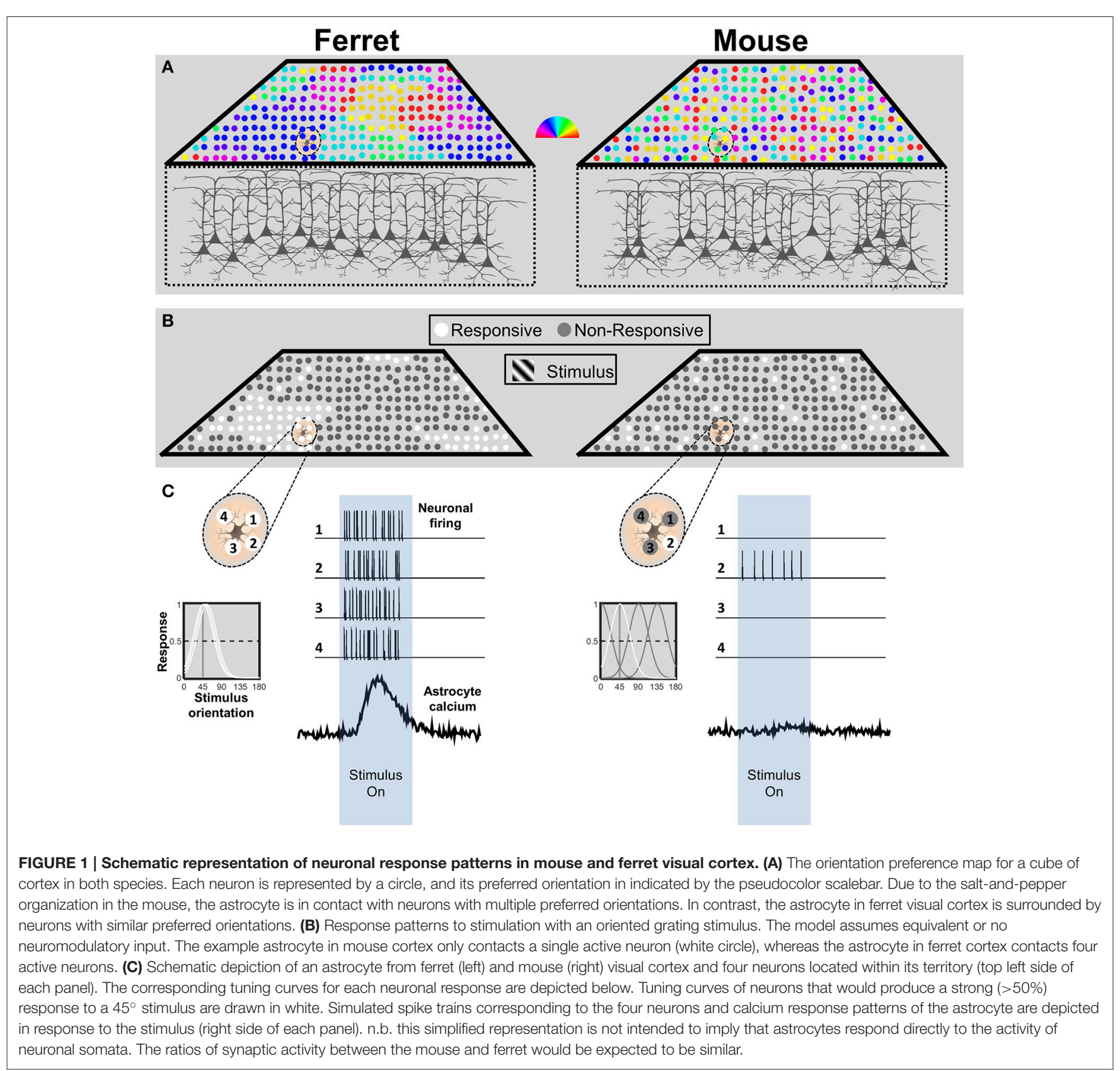

Saleem et al., 2013). Locomotion increases activity of neurons in V1 and also corresponds to different brain states, including different electroencephalogram (EEG) states (Ayaz et al., 2013; Saleem et al., 2013) and neuromodulator tone (Niell and Stryker, 2010). Either of these could affect astrocyte responsiveness. If we consider astrocytes as integrators of neuronal activity, then these results could explain why mouse V1 astrocytes are not responsive to visual stimulation alone in stationary resting or sedated conditions.

If indeed species differences in neuronal circuit organization account for observed species differences in visual cortical astrocyte responses, can we learn anything from other sensory systems, in which rodents have a spatially organized stimulus representation? In the olfactory bulb, rodents have a clear organization over the different layers of the bulb and odors are mapped onto different glomeruli (Stewart et al., 1979; Greer et al., 1982; Lancet et al., 1982). Thus, presentation of an odor elicits concerted responses from local populations of neurons (Uchida et al., 2000, 2014) and calcium elevations in astrocytes also in vivo (Petzold et al., 2008; Otsu et al., 2015). In the somatosensory cortex, there is a precise topographic representation of the body surface, including the whisker field, which is often referred to as barrel cortex (Woolsey and Van der Loos, 1970). In the rodent somatosensory cortex, responses of astrocytes to sensory 
stimulation have been readily observed in vivo (Wang et al., 2006; Takata et al., 2011; Lind et al., 2013; Stobart et al., 2016) but see (Ding et al., 2013; Nizar et al., 2013). These comparisons lend support to the notion that the difference between astrocyte responses to visual stimuli in ferrets and mice is not necessarily species dependent but rather is determined by the organization of the neuronal circuitry in which it is embedded.

\section{VISUAL SYSTEM IN FERRETS AND RODENTS: ASTROCYTE ORGANIZATION}

It remains possible that some observed differences are also a reflection of astrocyte specializations. Astrocyte diversity across brain regions and species is well-documented, and it is commonly thought that astrocyte spatial distribution and morphology are well-suited to accomplish their circuit-specific functions (De Saint Jan and Westbrook, 2005; Houades et al., 2008; Roux et al., 2011). Rodent cortical astrocytes are small cells with processes that tile gray matter of the brain (Bushong et al., 2002; Ogata and Kosaka, 2002). Each astrocyte covers $\sim 75,000 \mu \mathrm{m}^{3}$ of the gray matter in the hippocampus (Ogata and Kosaka, 2002; Bushong et al., 2002) and $66,000 \mu \mathrm{m}^{3}$ in visual cortex (López-Hidalgo et al., 2016). Here, astrocytes establish exclusive territories so their processes overlap with their neighbors by $<5 \%$ (LópezHidalgo et al., 2016).

Astrocytes from ferret visual cortex are considerably different from their counterparts in rodents. In ferrets, astrocytes are twice as big ( $\sim 120,000$ vs. $\left.66,000 \mu \mathrm{m}^{3}\right)$, less spherical and have a wide variety of shapes (López-Hidalgo et al., 2016). Their processes extend up to $30 \mu \mathrm{m}$ away from the soma and they overlap with the processes of 6-8 neighboring astrocytes and each astrocyte shares almost $50 \%$ of its territory with the processes of its neighbors (López-Hidalgo et al., 2016). Although, the functional consequence of exclusive territories is unclear, a larger astrocyte would interact with a larger number of synchronously activated neurons. Assuming astrocytes are integrators of neuronal activity with a threshold amount of activity needed to elicit calcium responses, then more neuronal activity within its territory would facilitate reaching threshold.

\section{TECHNICAL CONSIDERATIONS}

Despite the arguments laid out above, there remain inconsistencies in the literature that are difficult to attribute solely to these factors. It is worth considering what other factors might give rise to different experimental outcomes. Astrocytes play an important role in physiological homeostasis of the nervous system and are extremely sensitive to a host of environmental factors including physical insult, $\mathrm{pH}$, temperature, extracellular ionic composition, and many others (Schipke et al., 2008; Verkhratsky et al., 2015; Mola et al., 2016). As a result, numerous subtle experimental factors can have important effects on the functional state of astrocytes, and lead to dramatically different results under seemingly similar experimental conditions.

Nearly all in vivo calcium imaging experiments of astrocytes involve making a craniotomy (and sometimes a durotomy), which necessarily risks insult or alteration of the physiological conditions at the brain surface. In the mouse, the preparation of the cranial window is particularly delicate. Due to the small distance between the skull and the brain, heating during drilling of the skull and brain compression during indentation of the thinned skull are a common source of variability from preparation to preparation. The material that contacts the brain surface can also have unintended impact on the extracellular milieu, with unanticipated consequences. In our experience, filling the craniotomy with agar dissolved in normal saline results in little to no astrocyte activity, whereas ACSF with proper ionic composition, $\mathrm{pH}$ and osmolarity leads to better results. An inert silicone plug, which is impenetrable by CSF, leads to more reliable astrocyte activity still (JS unpublished observations).

Another important factor is that under typical conditions, the brain temperature under a craniotomy in a mouse falls to $\sim 29^{\circ} \mathrm{C}$ (Schipke et al., 2008; Takata and Hirase, 2008; Kalmbach and Waters, 2012). This affects many biological processes to which astrocytes are likely to be sensitive. In particular, the frequency band of local potentials and the UP and DOWN state transitions were shown to depend on cortical temperature (Kalmbach and Waters, 2012). The authors' experience is that without actively maintaining the brain temperature near physiological temperature (Runyan et al., 2010), visually-evoked responses are often difficult to detect in neurons as well.

It is difficult to assess or predict the effects of these various factors on astrocyte physiology or calcium activity. Due to their sensitivity to so many factors, it is important to recognize that astrocyte activity is likely to be influenced to a much larger extent than neuronal activity. Because of the apparent high threshold for activating calcium signaling pathways, even small changes in neuronal activity levels may have a large impact on astrocyte activity.

\section{CONCLUSION}

Here, we have reviewed differences in the neuronal circuit and astrocyte organization in rodents vs. ferret visual cortex as well as methodological aspects that can explain the controversies in the literature regarding visual-evoked responses in astrocytes. We argue that one fundamental difference derives from the columnar vs. salt-and-pepper organization. In particular, visual stimulation with an oriented grating will elicit small, shortduration responses from a small proportion of synapses within the territory of an astrocyte in rodents, whereas the same stimulus will elicit robust, prolonged responses from a large fraction of the synapses within the territory of an astrocyte in ferret visual cortex.

We have emphasized these species differences in the visual cortex in part to clarify some discrepancies in the literature, but also as a starting point for understanding the general principles that govern the transfer of neuronal activity patterns to astrocyte calcium signaling events. Numerous lines of evidence suggest that the total amount of integrated local synaptic activity is necessary to exceed the threshold enabling calcium responses. This possibility is supported by the observation that astrocyte 
responses have been more reliably observed in rodents in areas with a spatially clustered sensory map, such as barrel cortex and olfactory bulb. A number of factors likely combine to set this threshold. Some of these may be considered physiologically relevant, such as neuromodulatory tone (Paukert et al., 2014), which can lower the threshold for synaptic activation either globally during alertness or arousal cues, or perhaps locally during learning or attentional states related to specific cortical areas. Other factors should likely be considered artifactual, owing to surgical or anesthesia conditions that put the cortex too far from the normal physiological state for the usual activation pathways to be activated.

Another important consideration is the spatial scale and localization of astrocyte calcium signals. Some in vitro experiments have indicated that small scale responses in the branches of astrocyte are responsive to low levels of neural activity (Di Castro et al., 2011; Panatier et al., 2011), whereas others have shown a similar sensitivity in branches and somata (Haustein et al., 2014). Thus, it remains an open question whether astrocyte processes have a lower threshold for sensory-evoked responses. Different methods for imaging calcium in astrocytes offer different resolutions for detecting subcellular calcium events in astrocytes. Many in vivo studies have used labeling with organic dyes that only afford limited resolution for calcium events that are not somatic. Few studies have systematically studied subcellular calcium sensory responses in vivo (Asada et al.,

\section{REFERENCES}

Ahmadlou, M., and Heimel, J. A. (2015). Preference for concentric orientations in the mouse superior colliculus. Nat. Commun. 6, 6773. doi: $10.1038 /$ ncomms7773

Alonso, J. M., Usrey, W. M., and Reid, R. C. (2001). Rules of connectivity between geniculate cells and simple cells in cat primary visual cortex. J. Neurosci. 21, 4002-4015.

Asada, A., Ujita, S., Nakayama, R., Oba, S., Ishii, S., Matsuki, N., et al. (2015). Subtle modulation of ongoing calcium dynamics in astrocytic microdomains by sensory inputs. Physiol Rep. 3:e12454. doi: 10.14814/phy2. 12454

Ayaz, A., Saleem, A. B., Schölvinck, M. L., and Carandini, M. (2013). Locomotion controls spatial integration in mouse visual cortex. Curr. Biol. 23, 890-894. doi: 10.1016/j.cub.2013.04.012

Bonder, D. E., and McCarthy, K. D. (2014). Astrocytic Gq-GPCR-linked IP3R-dependent $\mathrm{Ca}^{2+}$ signaling does not mediate neurovascular coupling in mouse visual cortex in vivo. J. Neurosci. 34, 13139-13150. doi: 10.1523/JNEUROSCI.2591-14.2014

Bushong, E. A., Martone, M. E., Jones, Y. Z., and Ellisman, M. H. (2002). Protoplasmic astrocytes in CA1 stratum radiatum occupy separate anatomical domains. J. Neurosci. 22, 183-192.

Chapman, B., Stryker, M. P., and Bonhoeffer, T. (1996). Development of orientation preference maps in ferret primary visual cortex. J. Neurosci. 16, 6443-6453.

Chen, N., Sugihara, H., Sharma, J., Perea, G., Petravicz, J., Le, C., et al. (2012). Nucleus basalis-enabled stimulus-specific plasticity in the visual cortex is mediated by astrocytes. Proc. Natl. Acad. Sci. U.S.A. 109, E2832-E2841. doi: 10.1073/pnas.1206557109

Cornell-Bell, A. H., Finkbeiner, S. M., Cooper, M. S., and Smith, S. J. (1990). Glutamate induces calcium waves in cultured astrocytes: long-range glial signaling. Science 247, 470-473. doi: 10.1126/science.1967852
2015; Stobart et al., 2016). It is possible that oriented stimuli would elicit highly localized responses in mouse cortical astrocytes, which might have been more difficult to detect (though see; Bonder and McCarthy, 2014; Asada et al., 2015).

In conclusion, we have highlighted here several aspects which could explain the differences between astrocyte calcium responses to visual stimuli measured in ferret and rodent visual cortex by us and others. We suggest that these differences reveal an important aspect of astrocyte signaling. Astrocytes require a minimum amount of neuronal activity to respond to sensory stimuli in vivo. This reinforces the idea that astrocytes are perhaps not involved in the millisecond level of perception, as neurons are, but rather have a role in plasticity or synchrony of neuronal activity, although this has yet to be shown in vivo.

\section{AUTHOR CONTRIBUTIONS}

$\mathrm{ML}, \mathrm{VK}$, and JS contributed to the conception and writing of the paper.

\section{FUNDING}

This work was supported by the National Eye Institute grant R01EY026977 (JS) and the Max Planck Florida Institute for Neuroscience.
Dani, J. W., and Smith, S. J. (1995). The triggering of astrocytic calcium waves by NMDA-induced neuronal activation. Ciba Found. Symp. 188, 195-205. discussion: 205-209.

Denk, W., Strickler, J. H., and Webb, W. W. (1990). Two-photon laser scanning fluorescence microscopy. Science 248, 73-76. doi: 10.1126/science.2321027

De Saint Jan, D., and Westbrook, G. L. (2005). Detecting activity in olfactory bulb glomeruli with astrocyte recording. J. Neurosci. 25, 2917-2924. doi: 10.1523/jneurosci.5042-04.2005

Di Castro, M. A., Chuquet, J., Liaudet, N., Bhaukaurally, K., Santello, M., Bouvier, D., et al. (2011). Local $\mathrm{Ca}^{2+}$ detection and modulation of synaptic release by astrocytes. Nat. Neurosci. 14, 1276-1284. doi: 10.1038/nn.2929

Ding, F., O’Donnell, J., Thrane, A. S., Zeppenfeld, D., Kang, H., Xie, L., et al. (2013). $\alpha 1$-Adrenergic receptors mediate coordinated $\mathrm{Ca}^{2+}$ signaling of cortical astrocytes in awake, behaving mice. Cell Calcium 54, 387-394. doi: 10.1016/j.ceca.2013.09.001

Dräger, U. C. (1975). Receptive fields of single cells and topography in mouse visual cortex. J. Comp. Neurol. 160, 269-290. doi: 10.1002/cne.901600302

Durand, S., Iyer, R., Mizuseki, K., de Vries, S., Mihalas, S., and Reid, R. C. (2016). A Comparison of visual response properties in the lateral geniculate nucleus and primary visual cortex of awake and anesthetized mice. J. Neurosci. 36, 12144-12156. doi: 10.1523/JNEUROSCI.1741-16.2016

Ellis, E. M., Gauvain, G., Sivyer, B., and Murphy, G. J. (2016). Shared and distinct retinal input to the mouse superior colliculus and dorsal lateral geniculate nucleus. J. Neurophysiol. 116, 602-610. doi: 10.1152/jn.00227.2016

Feinberg, E. H., and Meister, M. (2015). Orientation columns in the mouse superior colliculus. Nature 519, 229-232. doi: 10.1038/nature14103

Fiacco, T. A., and McCarthy, K. D. (2004). Intracellular astrocyte calcium waves in situ increase the frequency of spontaneous AMPA receptor currents in CA1 pyramidal neurons. J. Neurosci. 24, 722-732. doi: 10.1523/JNEUROSCI.2859-03.2004

Finkbeiner, S. (1992). Calcium waves in astrocytes-filling in the gaps. Neuron 8, 1101-1108. doi: 10.1016/0896-6273(92)90131-v 
Gauvain, G., and Murphy, G. J. (2015). Projection-specific characteristics of retinal input to the brain. J. Neurosci. 35, 6575-6583. doi: 10.1523/jneurosci.4298-14.2015

Ghosh, A., Wyss, M. T., and Weber, B. (2013). Somatotopic astrocytic activity in the somatosensory cortex. Glia 61, 601-610. doi: 10.1002/glia.22458

Giaume, C., and Venance, L. (1998). Intercellular calcium signaling and gap junctional communication in astrocytes. Glia 24, 50-64. doi: 10.1002/(SICI)1098-1136(199809)24:1<50::AID-GLIA6>3.0.CO;2-4

Greer, C. A., Stewart, W. B., Teicher, M. H., and Shepherd, G. M. (1982). Functional development of the olfactory bulb and a unique glomerular complex in the neonatal rat. J. Neurosci. 2, 1744-1759.

Grinvald, A., Lieke, E., Frostig, R. D., Gilbert, C. D., and Wiesel, T. N. (1986). Functional architecture of cortex revealed by optical imaging of intrinsic signals. Nature 324, 361-364. doi: 10.1038/324361a0

Han, J., Kesner, P., Metna-Laurent, M., Duan, T., Xu, L., Georges, F., et al. (2012). Acute cannabinoids impair working memory through astroglial CB1 receptor modulation of hippocampal LTD. Cell 148, 1039-1050. doi: 10.1016/j.cell.2012.01.037

Haustein, M. D., Kracun, S., Lu, X. H., Shih, T., Jackson-Weaver, O., Tong, X., et al. (2014). Conditions and constraints for astrocyte calcium signaling in the hippocampal mossy fiber pathway. Neuron 82, 413-429. doi: 10.1016/j.neuron.2014.02.041

Helmchen, F., and Denk, W. (2005). Deep tissue two-photon microscopy. Nat. Methods 2, 932-940. doi: 10.1038/nmeth818

Hirsch, J. A., Alonso, J. M., Reid, R. C., and Martinez, L. M. (1998). Synaptic integration in striate cortical simple cells. J. Neurosci. 18, 9517-9528.

Hofbauer, A., and Dräger, U. C. (1985). Depth segregation of retinal ganglion cells projecting to mouse superior colliculus. J. Comp. Neurol. 234, 465-474. doi: 10.1002/cne.902340405

Houades, V., Koulakoff, A., Ezan, P., Seif, I., and Giaume, C. (2008). Gap junctionmediated astrocytic networks in the mouse barrel cortex. J. Neurosci. 28, 5207-5217. doi: 10.1523/jneurosci.5100-07.2008

Hubel, D. H., and Wiesel, T. N. (1962). Receptive fields, binocular interaction and functional architecture in the cat's visual cortex. J. Physiol. 160, 106-154. doi: 10.1113/jphysiol.1962.sp006837

Inayat, S., Barchini, J., Chen, H., Feng, L., Liu, X., and Cang, J. (2015). Neurons in the most superficial lamina of the mouse superior colliculus are highly selective for stimulus direction. J. Neurosci. 35, 7992-8003. doi: 10.1523/jneurosci.0173-15.2015

Kalmbach, A. S., and Waters, J. (2012). Brain surface temperature under a craniotomy. J. Neurophysiol. 108, 3138-3146. doi: 10.1152/jn.00557.2012

Keller, G. B., Bonhoeffer, T., and Hübener, M. (2012). Sensorimotor mismatch signals in primary visual cortex of the behaving mouse. Neuron $74,809-815$. doi: 10.1016/j.neuron.2012.03.040

Kondo, S., Yoshida, T., and Ohki, K. (2016). Mixed functional microarchitectures for orientation selectivity in the mouse primary visual cortex. Nat. Commun. 7:13210. doi: 10.1038/ncomms 13210

Lancet, D., Greer, C. A., Kauer, J. S., and Shepherd, G. M. (1982). Mapping of odor-related neuronal activity in the olfactory bulb by high-resolution 2-deoxyglucose autoradiography. Proc. Natl. Acad. Sci. U.S.A. 79, 670-674. doi: 10.1073/pnas.79.2.670

Lee, H. S., Ghetti, A., Pinto-Duarte, A., Wang, X., Dziewczapolski, G., Galimi, F., et al. (2014). Astrocytes contribute to gamma oscillations and recognition memory. Proc. Natl. Acad. Sci. U.S.A. 111, E3343-E3352. doi: 10.1073/pnas.1410893111

Lima, A., Sardinha, V. M., Oliveira, A. F., Reis, M., Mota, C., Silva, M. A., et al. (2014). Astrocyte pathology in the prefrontal cortex impairs the cognitive function of rats. Mol. Psychiatry 19, 834-841. doi: 10.1038/mp.2013.182

Lind, B. L., Brazhe, A. R., Jessen, S. B., Tan, F. C., and Lauritzen, M. J. (2013). Rapid stimulus-evoked astrocyte $\mathrm{Ca}^{2+}$ elevations and hemodynamic responses in mouse somatosensory cortex in vivo. Proc. Natl. Acad. Sci. U.S.A. 110, E4678-E4687. doi: 10.1073/pnas.1310065110

Linden, R., and Perry, V. H. (1983a). Retrograde and anterograde-transneuronal degeneration in the parabigeminal nucleus following tectal lesions in developing rats. J. Comp. Neurol. 218, 270-281. doi: 10.1002/cne.902180304

Linden, R., and Perry, V. H. (1983b). Massive retinotectal projection in rats. Brain Res. 272, 145-149. doi: 10.1016/0006-8993(83)90371-2
López-Hidalgo, M., Hoover, W. B., and Schummers, J. (2016). Spatial organization of astrocytes in ferret visual cortex. J. Comp. Neurol. 524, 3561-3576. doi: $10.1002 /$ cne. 24015

López-Hidalgo, M., Salgado-Puga, K., Alvarado-Martínez, R., Medina, A. C., Prado-Alcalá, R. A., and García-Colunga, J. (2012). Nicotine uses neuron-glia communication to enhance hippocampal synaptic transmission and long-term memory. PLoS ONE 7:e49998. doi: 10.1371/journal.pone.0049998

Mangini, N. J., and Pearlman, A. L. (1980). Laminar distribution of receptive field properties in the primary visual cortex of the mouse. J. Comp. Neurol. 193, 203-222. doi: 10.1002/cne.901930114

Martin, P. R. (1986). The projection of different retinal ganglion cell classes to the dorsal lateral geniculate nucleus in the hooded rat. Exp. Brain Res. 62, 77-88. doi: 10.1007/BF00237404

Matos, M., Shen, H. Y., Augusto, E., Wang, Y., Wei, C. J., Wang, Y. T., et al. (2015). Deletion of adenosine A2A receptors from astrocytes disrupts glutamate homeostasis leading to psychomotor and cognitive impairment: relevance to schizophrenia. Biol. Psychiatry 78, 763-774. doi: 10.1016/j.biopsych.2015.02.026

Min, R., and Nevian, T. (2012). Astrocyte signaling controls spike timingdependent depression at neocortical synapses. Nat. Neurosci. 15, 746-753. doi: $10.1038 / \mathrm{nn} .3075$

Mola, M. G., Sparaneo, A., Gargano, C. D., Spray, D. C., Svelto, M., Frigeri, A., et al. (2016). The speed of swelling kinetics modulates cell volume regulation and calcium signaling in astrocytes: a different point of view on the role of aquaporins. Glia 64, 139-154. doi: 10.1002/glia.22921

Nett, W. J., Oloff, S. H., and McCarthy, K. D. (2002). Hippocampal astrocytes in situ exhibit calcium oscillations that occur independent of neuronal activity. $J$. Neurophysiol. 87, 528-537. doi: 10.1152/jn.00268.2001

Niell, C. M., and Stryker, M. P. (2008). Highly selective receptive fields in mouse visual cortex. J. Neurosci. 28, 7520-7536. doi: 10.1523/jneurosci.0623-08.2008

Niell, C. M., and Stryker, M. P. (2010). Modulation of visual responses by behavioral state in mouse visual cortex. Neuron 65, 472-479. doi: 10.1016/j.neuron.2010.01.033

Nimmerjahn, A., Kirchhoff, F., Kerr, J. N., and Helmchen, F. (2004). Sulforhodamine 101 as a specific marker of astroglia in the neocortex in vivo. Nat. Methods 1, 31-37. doi: 10.1038/nmeth706

Nizar, K., Uhlirova, H., Tian, P., Saisan, P. A., Cheng, Q., Reznichenko, L., et al. (2013). In vivo stimulus-induced vasodilation occurs without IP3 receptor activation and may precede astrocytic calcium increase. J. Neurosci. 33, 8411-8422. doi: 10.1523/jneurosci.3285-12.2013

Ogata, K., and Kosaka, T. (2002). Structural and quantitative analysis of astrocytes in the mouse hippocampus. Neuroscience 113, 221-233. doi: 10.1016/s0306-4522(02)00041-6

Ohki, K., Chung, S., Ch'ng, Y. H., Kara, P., and Reid, R. C. (2005). Functional imaging with cellular resolution reveals precise micro-architecture in visual cortex. Nature 433, 597-603. doi: 10.1038/nature03274

Ohki, K., and Reid, R. C. (2007). Specificity and randomness in the visual cortex. Curr. Opin. Neurobiol. 17, 401-407. doi: 10.1016/j.conb.2007.07.007

Olsen, M. L., Khakh, B. S., Skatchkov, S. N., Zhou, M., Lee, C. J., and Rouach, N. (2015). New insights on astrocyte ion channels: critical for homeostasis and neuron-glia signaling. J. Neurosci. 35, 13827-13835. doi: 10.1523/JNEUROSCI.2603-15.2015

Otsu, Y., Couchman, K., Lyons, D. G., Collot, M., Agarwal, A., Mallet, J. M., et al. (2015). Calcium dynamics in astrocyte processes during neurovascular coupling. Nat. Neurosci. 18, 210-218. doi: 10.1038/nn.3906

Panatier, A., Vallée, J., Haber, M., Murai, K. K., Lacaille, J. C., and Robitaille, R. (2011). Astrocytes are endogenous regulators of basal transmission at central synapses. Cell 146, 785-798. doi: 10.1016/j.cell.2011.07.022

Parpura, V., Basarsky, T. A., Liu, F., Jeftinija, K., Jeftinija, S., and Haydon, P. G. (1994). Glutamate-mediated astrocyte-neuron signalling. Nature 369, 744-747. doi: $10.1038 / 369744 a 0$

Patrushev, I., Gavrilov, N., Turlapov, V., and Semyanov, A. (2013). Subcellular location of astrocytic calcium stores favors extrasynaptic neuron-astrocyte communication. Cell Calcium 54, 343-349. doi: 10.1016/j.ceca.2013.08.003

Paukert, M., Agarwal, A., Cha, J., Doze, V. A., Kang, J. U., and Bergles, D. E. (2014). Norepinephrine controls astroglial responsiveness to local circuit activity. Neuron 82, 1263-1270. doi: 10.1016/j.neuron.2014.04.038 
Perea, G., and Araque, A. (2007). Astrocytes potentiate transmitter release at single hippocampal synapses. Science 317, 1083-1086. doi: 10.1126/science.1144640

Petzold, G. C., Albeanu, D. F., Sato, T. F., and Murthy, V. N. (2008). Coupling of neural activity to blood flow in olfactory glomeruli is mediated by astrocytic pathways. Neuron 58, 897-910. doi: 10.1016/j.neuron.2008.04.029

Reid, R. C., and Alonso, J. M. (1995). Specificity of monosynaptic connections from thalamus to visual cortex. Nature 378, 281-284.

Ringach, D. L., Mineault, P. J., Tring, E., Olivas, N. D., Garcia-Junco-Clemente, P., and Trachtenberg, J. T. (2016). Spatial clustering of tuning in mouse primary visual cortex. Nat. Commun. 7:12270. doi: 10.1038/ncomms12270

Roux, L., Benchenane, K., Rothstein, J. D., Bonvento, G., and Giaume, C. (2011). Plasticity of astroglial networks in olfactory glomeruli. Proc. Natl. Acad. Sci. U.S.A. 108, 18442-18446. doi: 10.1073/pnas.1107386108

Rungta, R. L., Bernier, L. P., Dissing-Olesen, L., Groten, C. J., LeDue, J. M., Ko, R., et al. (2016). $\mathrm{Ca}^{2+}$ transients in astrocyte fine processes occur via $\mathrm{Ca}^{2+}$ influx in the adult mouse hippocampus. Glia 64, 2093-2103. doi: 10.1002/glia.23042

Runyan, C. A., Schummers, J., Van Wart, A., Kuhlman, S. J., Wilson, N. R., Huang, Z. J., et al. (2010). Response features of parvalbumin-expressing interneurons suggest precise roles for subtypes of inhibition in visual cortex. Neuron 67, 847-857. doi: 10.1016/j.neuron.2010.08.006

Saleem, A. B., Ayaz, A., Jeffery, K. J., Harris, K. D., and Carandini, M. (2013). Integration of visual motion and locomotion in mouse visual cortex. Nat. Neurosci. 16, 1864-1869. doi: 10.1038/nn.3567

Schipke, C. G., Heidemann, A., Skupin, A., Peters, O., Falcke, M., and Kettenmann, H. (2008). Temperature and nitric oxide control spontaneous calcium transients in astrocytes. Cell Calcium 43, 285-295. doi: 10.1016/j.ceca.2007.06.002

Schulz, K., Sydekum, E., Krueppel, R., Engelbrecht, C. J., Schlegel, F., Schröter, A., et al. (2012). Simultaneous BOLD fMRI and fiber-optic calcium recording in rat neocortex. Nat. Methods 9, 597-602. doi: 10.1038/nmeth.2013

Schummers, J., Yu, H., and Sur, M. (2008). Tuned responses of astrocytes and their influence on hemodynamic signals in the visual cortex. Science 320, 1638-1643. doi: $10.1126 /$ science. 1156120

Sekiguchi, K. J., Shekhtmeyster, P., Merten, K., Arena, A., Cook, D., Hoffman, E., et al. (2016). Imaging large-scale cellular activity in spinal cord of freely behaving mice. Nat. Commun. 7:11450. doi: 10.1038/ncomms11450

Shigetomi, E., Bushong, E. A., Haustein, M. D., Tong, X., Jackson-Weaver, O., Kracun, S., et al. (2013a). Imaging calcium microdomains within entire astrocyte territories and endfeet with GCaMPs expressed using adenoassociated viruses. J. Gen. Physiol. 141, 633-647. doi: 10.1085/jgp.201210949

Shigetomi, E., Jackson-Weaver, O., Huckstepp, R. T., O’Dell, T. J., and Khakh, B. S. (2013b). TRPA1 channels are regulators of astrocyte basal calcium levels and long-term potentiation via constitutive D-serine release. J. Neurosci. 33, 10143-10153. doi: 10.1523/JNEUROSCI.5779-12.2013

Srinivasan, R., Huang, B. S., Venugopal, S., Johnston, A. D., Chai, H., Zeng, $\mathrm{H}$., et al. (2015). $\mathrm{Ca}^{2+}$ signaling in astrocytes from $I p 3 r 2^{-/-}$mice in brain slices and during startle responses in vivo. Nat. Neurosci. 18, 708-717. doi: 10.1038/nn.4001

Stewart, W. B., Kauer, J. S., and Shepherd, G. M. (1979). Functional organization of rat olfactory bulb analysed by the 2-deoxyglucose method. J. Comp. Neurol. 185, 715-734. doi: 10.1002/cne.901850407

Stobart, J. L., Ferrari, K. D., Barrett, M. J. P., Stobart, M. J., Looser, Z. J., Saab, A. S., et al. (2016). Long-term in vivo calcium imaging of astrocytes reveals distinct cellular compartment responses to sensory stimulation. Cereb. Cortex doi: 10.1093/cercor/bhw366

Stosiek, C., Garaschuk, O., Holthoff, K., and Konnerth, A. (2003). In vivo twophoton calcium imaging of neuronal networks. Proc. Natl. Acad. Sci. U.S.A. 100, 7319-7324. doi: 10.1073/pnas.1232232100

Sun, W., McConnell, E., Pare, J. F., Xu, Q., Chen, M., Peng, W., et al. (2013). Glutamate-dependent neuroglial calcium signaling differs between young and adult brain. Science 339, 197-200. doi: 10.1126/science.1226740

Takano, T., He, W., Han, X., Wang, F., Xu, Q., Wang, X., et al. (2014). Rapid manifestation of reactive astrogliosis in acute hippocampal brain slices. Glia 62, 78-95. doi: 10.1002/glia.22588

Takata, N., and Hirase, H. (2008). Cortical layer 1 and layer $2 / 3$ astrocytes exhibit distinct calcium dynamics in vivo. PLoS ONE 3:e2525. doi: 10.1371/journal.pone.0002525

Takata, N., Mishima, T., Hisatsune, C., Nagai, T., Ebisui, E., Mikoshiba, K., et al. (2011). Astrocyte calcium signaling transforms cholinergic modulation to cortical plasticity in vivo. J. Neurosci. 31, 18155-18165. doi: 10.1523/JNEUROSCI.5289-11.2011

Uchida, N., Poo, C., and Haddad, R. (2014). Coding and transformations in the olfactory system. Annu. Rev. Neurosci. 37, 363-385. doi: 10.1146/annurev-neuro-071013-013941

Uchida, N., Takahashi, Y. K., Tanifuji, M., and Mori, K. (2000). Odor maps in the mammalian olfactory bulb: domain organization and odorant structural features. Nat. Neurosci. 3, 1035-1043. doi: 10.1038/79857

Valtcheva, S., and Venance, L. (2016). Astrocytes gate Hebbian synaptic plasticity in the striatum. Nat. Commun. 7:13845. doi: 10.1038/ncomms13845

Verkhratsky, A., Nedergaard, M., and Hertz, L. (2015). Why are astrocytes important? Neurochem. Res. 40, 389-401. doi: 10.1007/s11064-014-1403-2

Wang, X., Lou, N., Xu, Q., Tian, G. F., Peng, W. G., Han, X., et al. (2006). Astrocytic $\mathrm{Ca}^{2+}$ signaling evoked by sensory stimulation in vivo. Nat. Neurosci. 9, 816-823. doi: 10.1038/nn1703

Winship, I. R., Plaa, N., and Murphy, T. H. (2007). Rapid astrocyte calcium signals correlate with neuronal activity and onset of the hemodynamic response in vivo. J. Neurosci. 27, 6268-6272. doi: 10.1523/jneurosci.480106.2007

Woolsey, T. A., and Van der Loos, H. (1970). The structural organization of layer IV in the somatosensory region (SI) of mouse cerebral cortex. The description of a cortical field composed of discrete cytoarchitectonic units. Brain Res. 17, 205-242.

Zhang, K., Chen, C., Yang, Z., He, W., Liao, X., Ma, Q., et al. (2016). Sensory response of transplanted astrocytes in adult mammalian cortex in vivo. Cereb. Cortex 26, 3690-3704. doi: 10.1093/cercor/bhw213

Conflict of Interest Statement: The authors declare that the research was conducted in the absence of any commercial or financial relationships that could be construed as a potential conflict of interest.

Copyright (c) 2017 López-Hidalgo, Kellner and Schummers. This is an open-access article distributed under the terms of the Creative Commons Attribution License (CC $B Y)$. The use, distribution or reproduction in other forums is permitted, provided the original author(s) or licensor are credited and that the original publication in this journal is cited, in accordance with accepted academic practice. No use, distribution or reproduction is permitted which does not comply with these terms. 